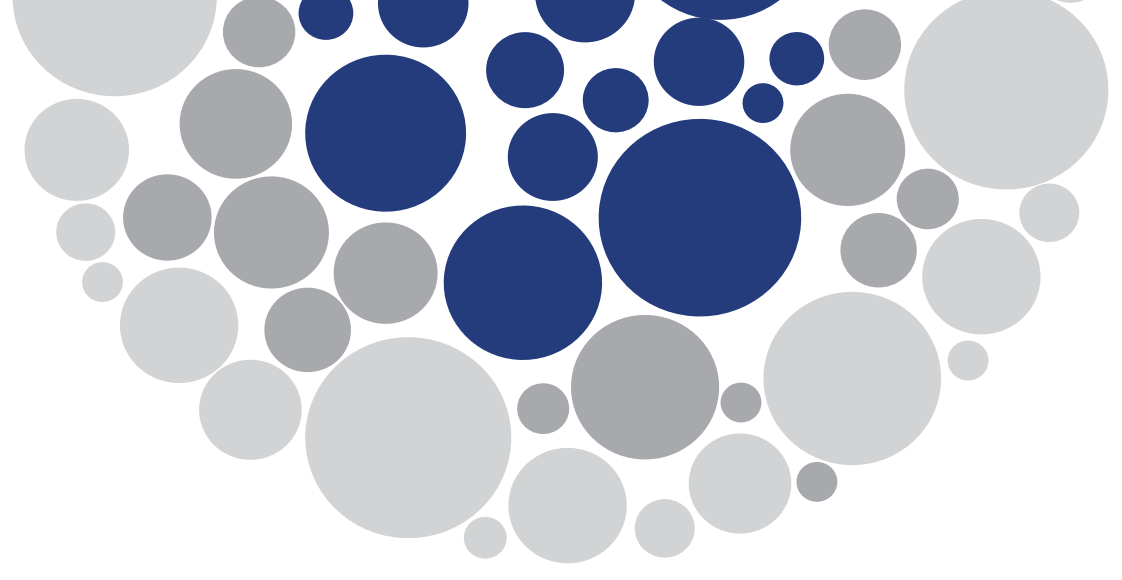

\title{
Comportamento espaço-temporal do oxigênio dissolvido e dos coliformes termotolerantes na região do médio/baixo curso do rio Paraíba do Sul, Norte Fluminense, Rio de Janeiro, Brasil
}

\begin{abstract}
Bruna Almeida Ribeiro ${ }^{a}$, Adriana Filgueira Leite ${ }^{b}$
a Universidade Federal Fluminense (UFF), Campos dos Goytacazes (RJ), Brasil. E-mail: bruna_almeida4@yahoo.com.br ${ }^{\mathrm{b}}$ Departamento de Geografia, Universidade Federal Fluminense (UFF), Campos dos Goytacazes (RJ), Brasil. E-mail: adrianafilgueiraleite@id.uff.br
\end{abstract}

\section{Introdução}

Nos últimos anos, os recursos hídricos vêm sendo deteriorados pela ação do homem, resultando em prejuízos na qualidade e na disponibilidade da água. Neste sentido, é notória a necessidade do monitoramento da qualidade da água, de modo a garantir que seus usos múltiplos não sejam comprometidos e que os impactos negativos sobre a sua qualidade sejam minimizados.

A qualidade da água é um fator indispensável para a sua utilização, visando atender às necessidades sociais e às atividades econômicas (urbanas, agrícolas e industriais). Esses usos têm sofrido restrições significativas em função de danos causados aos rios pelas intervenções humanas, as quais alteram a qualidade e a quantidade de água disponível para a utilização do homem. Todos esses dados apontam para uma realidade alarmante, mas que, apesar disso, tem sido muito menos discutida do que seria necessário em 
âmbito mundial, que é o fato de o planeta estar caminhando para uma tendência geral de escassez hídrica.

Essa escassez não é exatamente a falta da água no sentido pleno do termo, uma vez que, por questões físico-químicas, suas proporções na Terra são praticamente inalteráveis. Isso ocorre porque a água se movimenta no planeta por meio de um ciclo fechado - o ciclo hidrológico -, no qual esse elemento não sofre perdas nem ganhos em termos quantitativos. Nesse sentido, a escassez hídrica pode ocorrer sob duas formas: a primeira corresponde à restrição da disponibilidade de água para os usos múltiplos e pode ser expressa por meio da redução das vazões fluviais e pela necessidade de se fazer perfurações cada vez mais profundas nos solos para a instalação de poços, em razão do rebaixamento progressivo dos níveis freáticos; a segunda corresponde à perda da qualidade da água. Trata-se da sua deterioração a um nível tal de magnitude, que se torna impossível revertê-la por meio do uso de tecnologias.

De modo geral, as principais fontes de contaminantes dos recursos hídricos são os esgotos - em especial pelo fato de que no Brasil a maior parte deles é despejada nos corpos hídricos sem tratamento prévio -, os rejeitos industriais, os rejeitos de mineração, os agrotóxicos utilizados na agricultura e o chorume proveniente dos lixões.

A bacia hidrográfica do rio Paraíba do Sul, apesar de não estar entre as maiores do território brasileiro, pode ser considerada uma das mais importantes por estar localizada entre os três estados de maior pujança econômica nacional: São Paulo, Minas Gerais e Rio de Janeiro. Nesse sentido, mesmo que o rio em questão não integre a paisagem de nenhuma das regiões metropolitanas dos estados mencionados, ele perpassa diversos municípios de pequeno e médio portes que compõem o principal eixo industrial do país, posicionando-se entre São Paulo e Rio de Janeiro, ao longo da BR-116, sendo, portanto, receptor da maior parte dos efluentes industriais e urbanos, assim como da mineração e da agricultura, produzidos em contextos mais pontuais no âmbito da bacia.

Considerando que os níveis de tratamento de esgoto na bacia do rio Paraíba do Sul como um todo ainda são bastante incipientes quando se levam em conta os padrões internacionais de qualidade, ao alcançar a região do baixo curso, que é objeto de análise deste estudo, a água do rio em questão já se encontra bastante comprometida. A esse comprometimento se somam o fato de que a região mencionada apresenta um quadro de escassez hídrica, que se expressa por meio do declínio das vazões desse rio, e de que a sua população praticamente dobrou entre as décadas de 1960 e 2010 (LEITE, 2015).

Nesta conjuntura, verifica-se que os estudos de qualidade da água, que é um dos indicadores da sua disponibilidade no ambiente, conforme já mencionado, ganham especial relevância no contexto de escassez hídrica que se construiu historicamente na região do baixo rio Paraíba do Sul. Do ponto de vista da gestão dos recursos hídricos, estudos dessa natureza tendem a se tornar cada vez mais imprescindíveis, na medida em que os gestores necessitam de dados sobre a qualidade da água para planejar e implementar políticas públicas relacionadas à coleta, tratamento e descarte do esgoto, assim como de captação, tratamento e distribuição da água nos ambientes urbanos e rurais. Contudo, do ponto de vista geográfico, tais estudos tendem a ganhar centralidade no contexto da bacia mencionada, pois, ainda que o declínio das vazões a alcance como um todo, ele é mais crítico em determinados segmentos, a exemplo da região do médio/baixo curso. Considerando as históricas assimetrias de poder evidenciadas entre os diversos setores econômicos que se encontram ali representados, constata-se que as prioridades dos usos 
das águas tenderão a ser cada vez mais determinadas pelos grupos que são hegemônicos (LEITE, 2017).

Diante do exposto, este estudo se propõe a fazer uma análise da qualidade da água do rio Paraíba do Sul por meio dos parâmetros oxigênio dissolvido e coliformes termotolerantes no segmento que corresponde ao seu médio/baixo curso, localizado na região norte do estado do Rio de Janeiro, de tal modo a avaliar o seu comportamento espaço-temporal entre os anos de 2014 e 2019.

\section{Materiais e métodos}

\section{1 - Área de estudo}

A área onde o presente estudo foi realizado corresponde ao médio/baixo curso do rio Paraíba do Sul, no trecho compreendido pelos municípios de São Fidélis e Campos dos Goytacazes, ambos localizados no Norte Fluminense, Rio de Janeiro, Brasil (Figura 1).

No município de São Fidélis, a área que margeia o rio Paraíba do Sul é composta por relevo colinoso, e as planícies se encontram parcialmente confinadas em suas margens pelas encostas das colinas. O rio apresenta padrão entrelaçado e, conforme esperado,

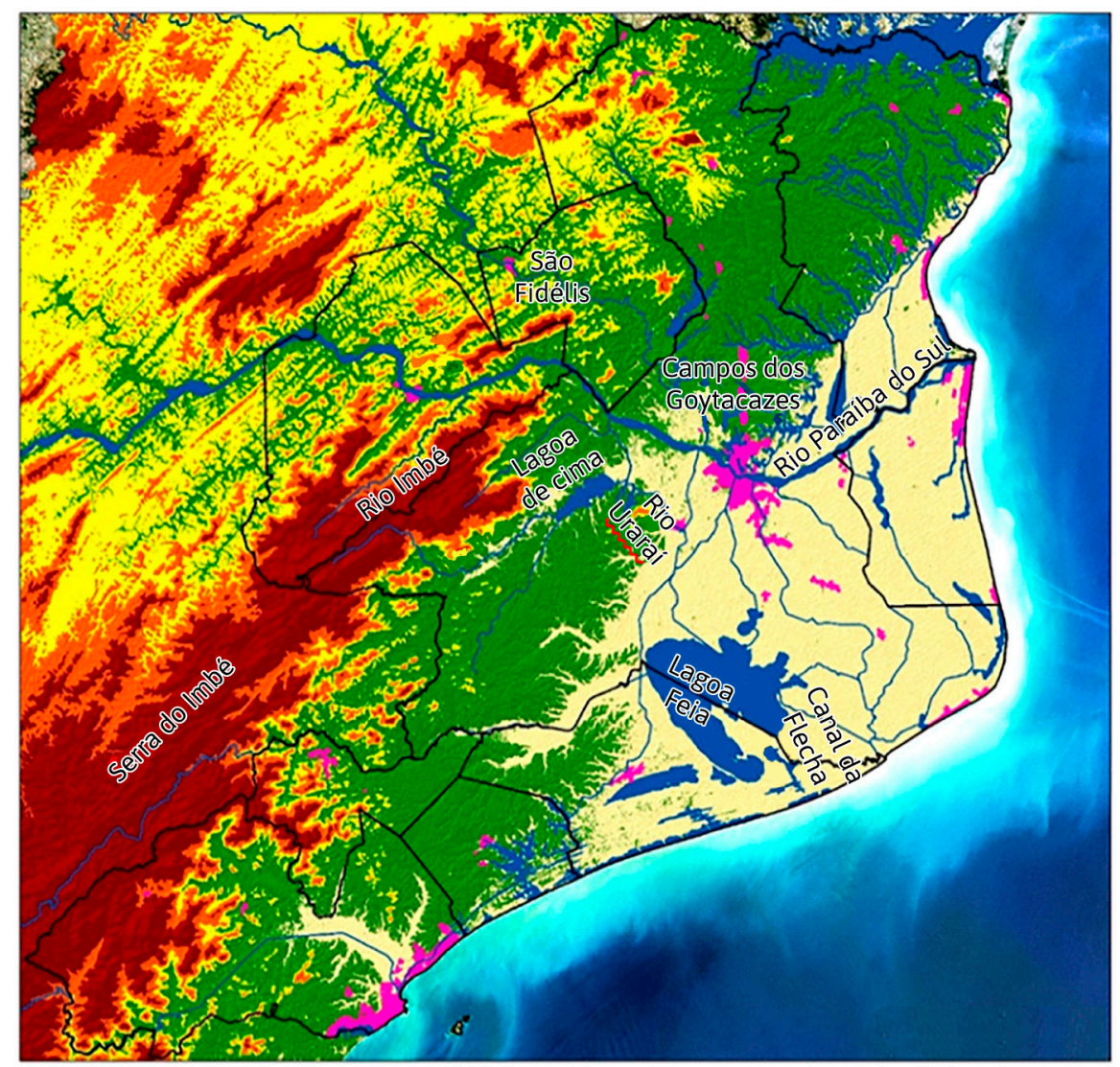

Domínios morfoesculturais da região norte fluminense

Legenda

$\sim 3$ Região norte fluminense

4 Ocupação urbana do norte fluminense

Corpos hídricos

Rios e canais

Lagos e lagoas

Domínios morfoesculturais

(3) 0-10 m - planície fluviomarinha

(4) $11-100 \mathrm{~m}$ - tabuleiros

(3) $101-200 \mathrm{~m}$ - morros

$3201-400 \mathrm{~m}$ - serras isoladas ou locais

$\checkmark$ >401 m - serras escarpadas

Retângulo envolvente

Norte

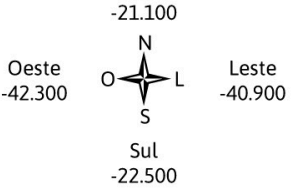

Sistema de coordenadas: GCS WGS 1984 Datum: WGS 1984

Unidades: graus decimais 1:500.00

Fonte: ALVES \& MIRO, 2015; ALVES et al, 2015; IBGE, 2013; INPE, 2015.

Elaboração: Walace Alves Nicking a partir do Centro de Informação e Dados de Campos - CIDAC - 2015

Figura 1 - Mapa de localização da região do médio/baixo curso do rio Paraíba do Sul (Norte Fluminense, Rio de Janeiro, Brasil). Fonte: NICKNIG (2016). 
uma abundante presença de ilhas ao longo do seu curso. Barras arenosas também são visíveis nos períodos de estiagem e de seca, quando se verifica uma redução significativa das vazões e dos níveis fluviais do Paraíba, como foi o caso da seca ocorrida entre os anos de 2014 e 2016. Ainda que a formação de barras e ilhas seja um processo natural concernente à dinâmica fluvial que caracteriza os ambientes com as características geomorfológicas que ali se encontram, verifica-se que a sua proliferação foi intensificada pelo desmatamento em larga escala desde o início da colonização, em especial nas áreas de encostas, na medida em que os sedimentos transportados pelos processos erosivos convergem para os corpos hídricos.

No município de Campos dos Goytacazes, pelo fato de o relevo apresentar-se predominantemente plano, a área que constitui as planícies do rio Paraíba do Sul não apresenta confinamento de suas margens. A margem esquerda situa-se sobre tabuleiros constituídos por sedimentos terciários da Formação Barreiras. Nessa margem, encontra-se também o ponto de deságue do rio Muriaé, que é o principal tributário do Paraíba nesse trecho da bacia. No que se refere à margem direita, constata-se que ela está posicionada sobre sedimentos quaternários de origem fluviomarinha, os quais foram ali depositados após sucessivos episódios de transgressões e regressões marinhas. O rio Paraíba do Sul, nesse segmento, apresenta um padrão de canal misto, que associa feições meandrantes e entrelaçadas.

É importante destacar que as intervenções feitas no rio Paraíba do Sul durante o século XX nos segmentos posicionados a montante da área estudada, especialmente a implantação de diversas hidrelétricas e de uma transposição de águas, exerceram impacto nos seus processos de sedimentação e, consequentemente, na formação de ilhas e barras fluviais em ambos os segmentos que são objeto desta análise. Isso ocorreu em resposta à redução das vazões fluviais promovida pela regularização do rio, que foi instituída pela gestão dos reservatórios (LEITE, 2019). Esse é um fator importante a ser levado em conta na análise deste trabalho, pelo fato de que a eficiência de um rio em promover a diluição dos esgotos que convergem para ele é fortemente influenciada pelo comportamento da vazão fluvial.

Outras intervenções de grande magnitude ocorreram também na área do entorno do rio Paraíba do Sul, no trecho compreendido entre Campos dos Goytacazes e São João da Barra. Em sua origem, a região como um todo se caracterizava por apresentar uma extensa superfície de brejos e lagoas (tanto de água doce quanto de água salgada), perenes e temporárias, que, desde o período colonial, passou por um amplo processo de drenagem, o qual ocorreu para que houvesse a ampliação das áreas a serem utilizadas pela agroindústria canavieira, a atividade econômica mais importante da região de meados do século XVIII (LAMEGO, 2007) até a década de 1980, momento em que entrou em declínio. A drenagem das superfícies foi feita por meio da implantação de uma extensa rede de canais artificiais, que, atualmente, apresenta $1.293 \mathrm{~km}$ de extensão (MENDONÇA, 2014). Goudie e Viles (2016) apontam que o processo de drenagem de superfícies brejais causa o rebaixamento dos níveis freáticos, principalmente em solos orgânicos, como é o caso de boa parte dos solos existentes na margem direita do rio Paraíba do Sul, que são compostos por turfas (FRANCHI et al., 2006). Considerando que os lençóis freáticos são responsáveis por manter a perenidade dos rios, verifica-se que o seu rebaixamento também foi responsável pela redução das vazões fluviais do rio Paraíba do Sul na região abrangida por seu médio/baixo curso (LEITE, não publicado). 


\section{2 - Levantamento e análise dos dados de qualidade da água}

Para a realização deste estudo, foram utilizados dados de oxigênio dissolvido (parâmetro físico-químico) e de coliformes termotolerantes (parâmetro biológico), provenientes de dois pontos da rede de monitoramento de qualidade da água do Instituto Estadual do Ambiente (INEA), localizados, respectivamente, em São Fidélis e em Campos dos Goytacazes (Figura 2), entre os anos de 2014 e 2019. Os dados em questão, assim como os métodos laboratoriais utilizados na sua determinação, encontram-se disponíveis no site da instituição (INSTITUTO ESTADUAL DO AMBIENTE, 2019). A seleção desses pontos teve por objetivo fazer uma comparação da qualidade da água entre o médio e o baixo curso do rio Paraíba do Sul. Para tanto, foram feitas análises espaço-temporais dos parâmetros ora mencionados. Assim sendo, os dados provenientes de cada ponto amostral considerado neste trabalho foram tabelados, submetidos a análises estatísticas de média, desvio padrão e coeficiente de variação e comparados entre si.

\section{Resultados e discussão}

\section{1 - Oxigênio dissolvido}

O oxigênio é um gás cuja principal origem é a atmosfera. Nesse sentido, Von Sperling (2014) afirma que as águas constituem ambientes bastante pobres em oxigênio, em virtude da

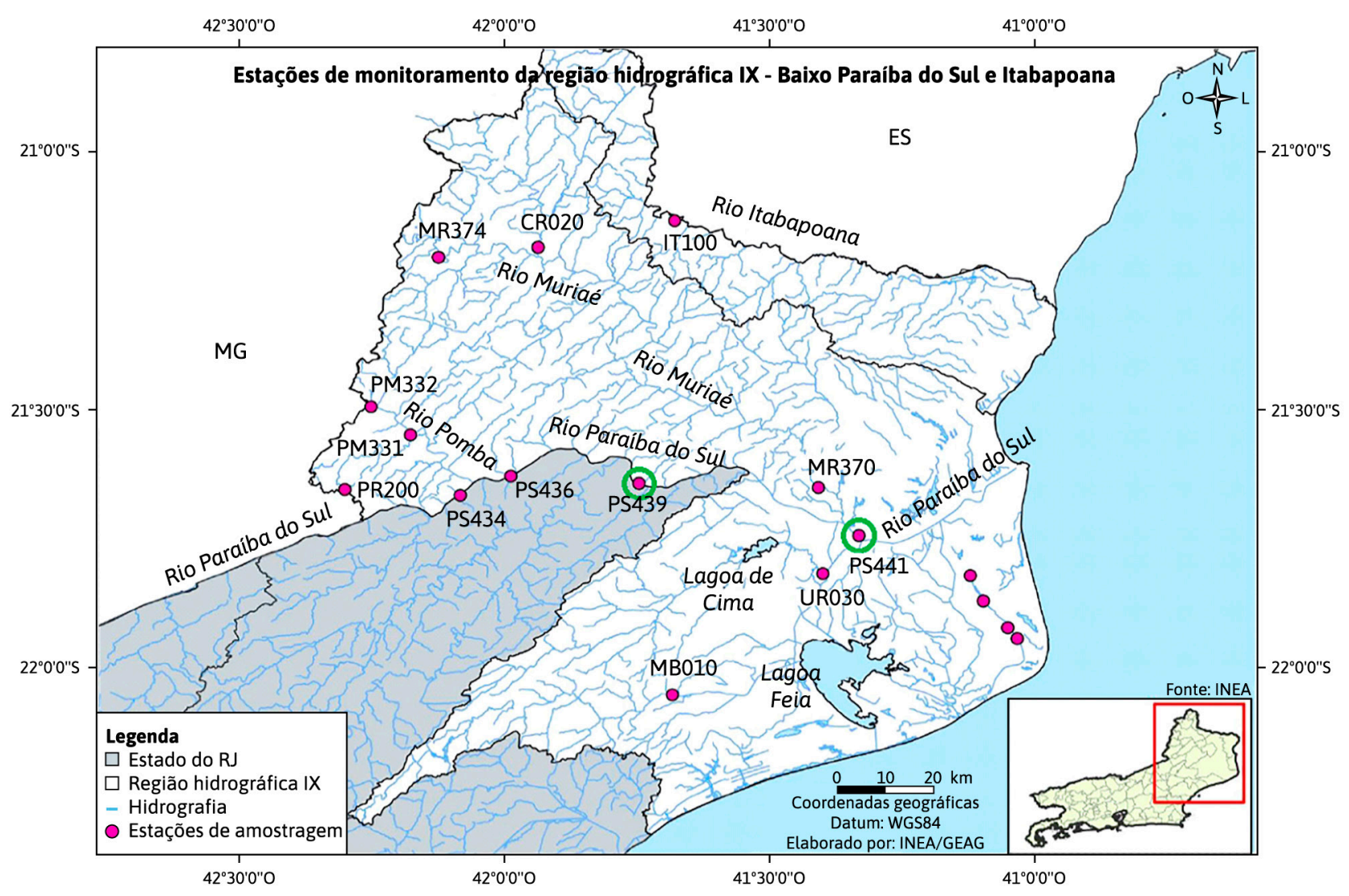

Figura 2 - Pontos de amostragem da rede de monitoramento de qualidade da água realizado pelo INEA. Os pontos que apresentam os círculos de cor verde correspondem aos locais cujos dados foram analisados neste estudo.

Fonte: Instituto Estadual do Ambiente (2019). 
sua baixa solubilidade. Enquanto no ar a sua concentração é da ordem de $270 \mathrm{mg} / \mathrm{L}$, na água, em condições normais de temperatura e pressão, a sua concentração se reduz para aproximadamente $9 \mathrm{mg} / \mathrm{L}$.

Von Sperling (2014) afirma também que a reaeração atmosférica é frequentemente o principal fator responsável pela introdução de oxigênio no meio líquido. Neste sentido, a transferência do oxigênio da fase gasosa para a fase líquida ocorreria basicamente por meio de dois mecanismos: a difusão molecular e a difusão turbulenta. No que se refere à difusão molecular, trata-se do processo que predomina nos corpos hídricos cujas águas apresentam baixas velocidades de deslocamento, como no caso dos ambientes lacustres. Consiste na tendência que as substâncias têm de se espalhar uniformemente por todo o espaço disponível, sendo, portanto, bastante lento e requerendo muito tempo para que um gás atinja as camadas mais profundas. $O$ vento é um fator que age de tal modo a acelerar a ação desse mecanismo nos contextos em que ele prevalece. Quanto à difusão turbulenta, considerada mais eficiente, refere-se ao mecanismo que promove a reaeração das águas a partir dos processos de criação de interfaces e de sua respectiva renovação. Tal fenômeno é determinado pelas mais altas velocidades das correntes, uma vez que propiciam condições de alta turbulência da água. Esse seria o caso, por exemplo, de um rio com menor profundidade e com corredeiras.

Segundo Esteves e Furtado (2011), as concentrações de oxigênio dissolvido são variáveis verticalmente na coluna d'água, sendo mais altas nas superfícies dos corpos hídricos e ínfimas nos leitos fluviais e lacustres. Essa seria uma consequência do fato de que a difusão do oxigênio dentro de um corpo de água se dá, principalmente, pelo seu transporte em massas d'água (por difusão turbulenta), uma vez que a difusão molecular é insignificante. Contudo, verifica-se também que, além de as superfícies dos corpos hídricos estarem em contato direto com a atmosfera, sendo, portanto, mais favorecidas pelos mecanismos de aeração, há variações verticais na velocidade da corrente fluvial e, consequentemente, da turbulência da água. De acordo com Summerfield (1991), a velocidade do fluxo da corrente é influenciada pela declividade, assim como pela rugosidade e pela forma da seção transversal do canal. Os canais naturais quase invariavelmente têm superfícies rugosas que induzem perdas significativas de energia de atrito e causam uma redução na velocidade do fluxo, especialmente perto do limite do canal (bordas e leito).

Quanto à sua influência sobre a qualidade da água, constata-se, de acordo com Von Sperling (2018), que o oxigênio dissolvido é de essencial importância para os organismos aeróbios. Durante a estabilização da matéria orgânica, as bactérias fazem uso do oxigênio nos seus processos respiratórios, podendo vir a causar uma redução da sua concentração no meio. A matéria orgânica corresponde a todo o material de origem vegetal ou animal produzido no próprio ambiente aquático (autóctone) ou introduzido nele por meio de despejos ou carreamento, ou seja, pelo arraste por água de chuva (alóctone) (COMPANHIA AMBIENTAL DO ESTADO DE SÃO PAULO, 2021). A matéria orgânica proveniente dos esgotos se apresenta sob duas formas: em suspensão (ou particulada), que tende a sedimentar no corpo d'água, formando o lodo de fundo; e dissolvida (ou solúvel), que, conjuntamente com a matéria suspensa de pequenas dimensões (dificilmente sedimentável), permanece na massa líquida. Dependendo da magnitude do consumo do oxigênio dissolvido pelas bactérias, podem vir a morrer diversos seres aquáticos, inclusive os peixes. Caso o oxigênio seja totalmente consumido, são produzidas condições anaeróbias, com possível geração de maus odores. Por esse motivo, o oxigênio dissolvido 
é o principal parâmetro de caracterização dos efeitos da poluição das águas por despejos orgânicos (VON SPERLING, 2018).

Os teores de oxigênio dissolvido também expressam a capacidade de autodepuração dos corpos hídricos. O potencial de autodepuração refere-se à habilidade que os ambientes aquáticos têm de estabilizar a matéria orgânica que ali se encontra. Esse fenômeno ocorre à medida que as bactérias consomem o oxigênio dissolvido durante o processo de decomposição da matéria orgânica, convertendo-a em substâncias como gás carbônico e água (estabilização), que são estáveis e não prejudiciais ao ambiente do ponto de vista ecológico (VON SPERLING, 2018). Sendo assim, ele também é fortemente influenciado pelas vazões fluviais, pois, conforme já mencionado, os processos de aeração e reaeração dos corpos hídricos são determinados pela turbulência das correntes. Nesse sentido, enquanto baixas vazões determinam taxas mais baixas de aeração, o oposto acontece quando as vazões são altas.

Contudo, o conceito de autodepuração apresenta certa relatividade, pois um corpo d'água pode ser considerado depurado sob determinado aspecto e não o ser em outros, a exemplo dos padrões de salubridade, apresentando, assim, organismos patogênicos. Do ponto de vista prático, deve-se considerar que um corpo d'água ou trecho de rio está depurado quando suas características não são mais conflitantes com o tipo de uso que para ele se encontra previsto em lei (VON SPERLING, 2018).

No que se refere aos padrões considerados aceitáveis para o oxigênio dissolvido, percebe-se que a sua concentração média ao nível do mar é de 9,2 mg/L. Assim sendo, enquanto as concentrações inferiores a esse valor são indicativas da presença de matéria orgânica nos corpos hídricos, originária primordialmente de esgotos, as superiores constituem indícios do elevado acúmulo de algas (que realizam fotossíntese e produzem oxigênio puro). Quando os valores de oxigênio dissolvido se encontram em torno de 4-5 mg/L, os peixes mais exigentes morrem, e quando alcança o valor de $2 \mathrm{mg} / \mathrm{L}$, inviabiliza-se a existência de todos os peixes, incluindo os mais tolerantes à baixa oxigenação (VON SPERLING, 2018). Quanto aos padrões especificados pela Resolução CONAMA 357/2005 (BRASIL, 2005), que é a norma que regulamenta os padrões de qualidade da água utilizados no Brasil, constata-se que, para as águas doces, as concentrações de oxigênio dissolvido nas águas de classe 1 não devem ser inferiores a $6 \mathrm{mg} / \mathrm{L}$; nas águas de classe 2 , não devem ser inferiores a $5 \mathrm{mg} / \mathrm{L}$; e nas águas de classe 3 , não devem ser inferiores a $4 \mathrm{mg} / \mathrm{L}^{1}$. No que diz respeito ao rio Paraíba do Sul, verifica-se que o seu enquadramento é de classe 2 em São Fidélis e de classe 3 em Campos dos Goytacazes (COMITÊ DE INTEGRAÇÃO DA BACIA HIDROGRÁFICA DO RIO PARAÍBA DO SUL, 2020).

No que concerne aos dados analisados neste estudo, observa-se que, em ambos os pontos de amostragem do rio Paraíba do Sul, localizados nos municípios de São Fidélis e Campos dos Goytacazes, são identificadas concentrações inferiores a 9,2 mg/L de oxigênio dissolvido, as quais são indicativas da presença de esgotos nas águas. Trata-se de um resultado que já poderia ser esperado, considerando que nenhum dos municípios mencionados coleta e trata $100 \%$ do esgoto que produz (Figura 3). Contudo, apesar disso, não foram ali detectadas concentrações baixas o bastante que pudessem

${ }^{1}$ De acordo com a Resolução CONAMA 357/2005, as águas doces correspondem às águas com salinidade igual ou inferior a $0,5 \%$ e são divididas em classe especial e classes 1, 2 e 3 . Quanto ao uso para abastecimento humano, as águas da classe especial para serem consumidas necessitam passar somente por desinfecção; as de classe 1, por tratamento simplificado; as de classe 2, por tratamento convencional; e as de classe 3, por tratamento convencional ou avançado. 


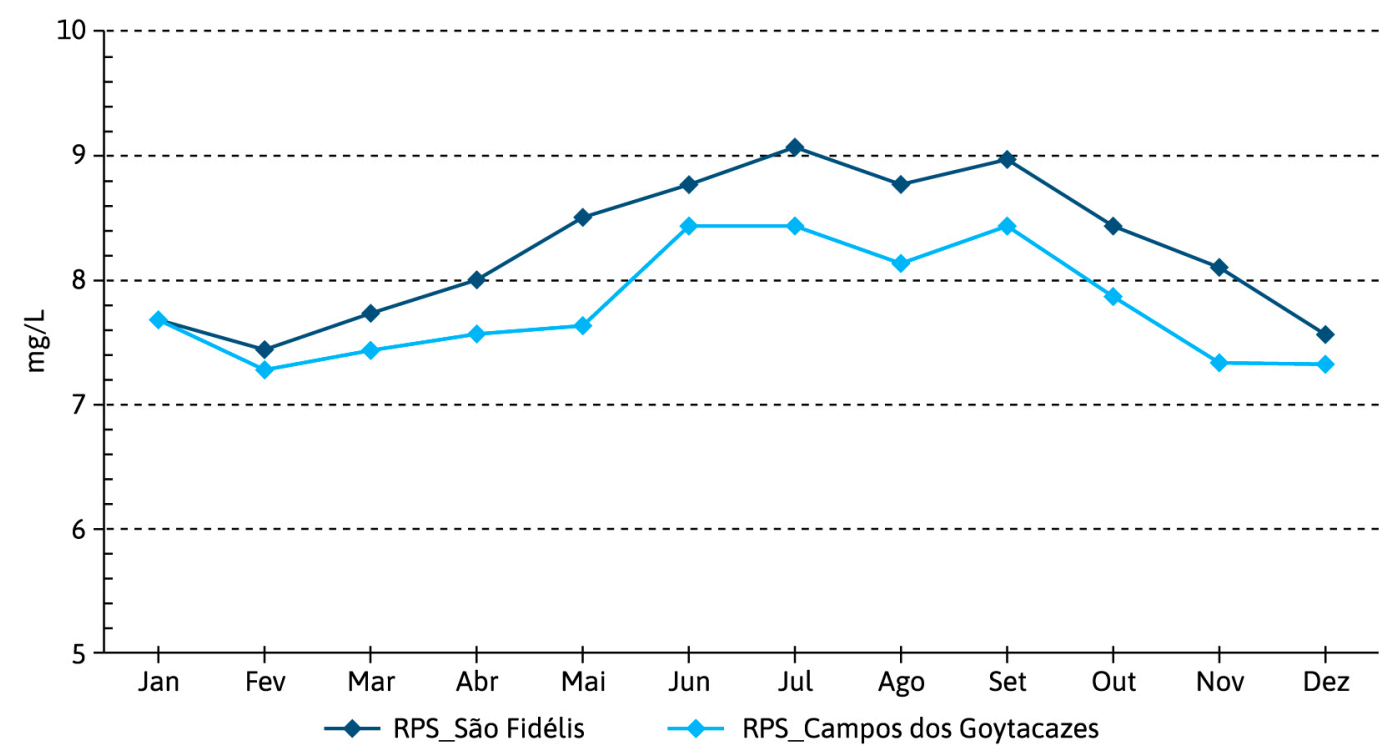

Figura 3 - Comportamento sazonal do oxigênio dissolvido (em $\mathrm{mg} / \mathrm{L}$ ) nos pontos amostrais do rio Paraíba do Sul (RPS), localizados nos municípios de São Fidélis e Campos dos Goytacazes (Rio de Janeiro, Brasil), referente à série amostral 2014-2019. Para tanto, foram utilizados os dados das médias mensais. Fonte: Instituto Estadual do Ambiente (2019).

comprometer a vida dos organismos aquáticos. Nota-se também que ambos os municípios apresentam concentrações de oxigênio dissolvido que são compatíveis com a sua classe de enquadramento.

A Figura 3 também apresenta duas tendências fundamentais. A primeira refere-se ao fato de que as concentrações médias mensais de oxigênio dissolvido são mais altas em São Fidélis do que em Campos dos Goytacazes. Apesar de a cidade de São Fidélis dispor de um serviço de saneamento que é muito menos eficiente que o de Campos dos Goytacazes, na medida em que despeja todo o esgoto que coleta nos corpos hídricos (Tabela 1), enquanto Campos dos Goytacazes coleta cerca de $80 \%$ do esgoto que produz e trata $100 \%$ do que coleta (Tabela 2), quando se levam em consideração as diferenças entre os totais populacionais de ambos os municípios, verifica-se que Campos dos Goytacazes ainda assim contribui proporcionalmente com mais esgotos para o rio Paraíba do Sul que São Fidélis ${ }^{2}$ (Tabelas 1 e 2). Outro aspecto importante é que, tanto em São Fidélis quanto em Campos, a população é predominantemente urbana (cerca de 79\% e 90\%, respectivamente, em 2019) e se concentra nas margens do rio (Figura 1), proximidade essa que favorece o seu uso como receptáculo de dejetos.

Os dados em questão mostram que, apesar da maior eficiência do serviço de saneamento de Campos dos Goytacazes, que determina uma concentração menor de bactérias decompositoras nos corpos hídricos - conforme será visto no item referente aos coliformes termotolerantes -, as mais elevadas vazões fluviais do rio Paraíba do Sul identificadas neste município em relação às vazões registradas em São Fidélis (COMITÊ DA BACIA HIDROGRÁFICA DO BAIXO RIO PARAÍBA DO SUL E ITABAPOANA, 2014) promovem ali uma turbulência maior do fluxo fluvial, especialmente

2 O serviço de saneamento em São Fidélis é realizado pela prefeitura municipal do município, e em Campos dos Goytacazes, pela empresa Águas do Paraíba S/A. 
Tabela 1 - Dados populacionais e de saneamento do município de São Fidélis (Rio de Janeiro, Brasil), referente à série amostral $2014-2019$.

\begin{tabular}{|c|c|c|c|c|c|c|c|}
\hline $\begin{array}{l}\text { Ano de } \\
\text { referência }\end{array}$ & $\begin{array}{l}\text { Pop. total do } \\
\text { município }\end{array}$ & $\begin{array}{l}\text { Pop. urbana } \\
\text { do município }\end{array}$ & $\begin{array}{l}\text { Pop. urbana } \\
\text { (\%) }\end{array}$ & $\begin{array}{l}\text { Pop. total } \\
\text { atendida } \\
\text { com esgot. } \\
\text { sanit. }\end{array}$ & $\begin{array}{l}\text { Pop. total } \\
\text { atendida } \\
\text { com esgot. } \\
\text { sanit. (\%) }\end{array}$ & $\begin{array}{l}\text { Vol. de } \\
\text { esgotos } \\
\text { coletado } \\
\text { (1.000 m/ano) }\end{array}$ & $\begin{array}{l}\text { Vol. de } \\
\text { esgotos } \\
\text { tratado } \\
\left(1.000 \mathrm{~m}^{3} / \text { ano }\right)\end{array}$ \\
\hline 2019 & 38.669 & 30.569 & 79,1 & 33.850 & 87,54 & $1.968,22$ & 0 \\
\hline 2018 & 38.626 & 30.535 & 79,1 & 33.850 & 87,64 & $1.968,22$ & 0 \\
\hline 2017 & 37.689 & 29.794 & 79,1 & 33.800 & 89,68 & $1.958,22$ & 0 \\
\hline 2016 & 37.696 & 29.800 & 79,1 & 32.798 & 87,01 & $1.758,21$ & 0 \\
\hline 2015 & 37.703 & 29.805 & 79,1 & 32.798 & 86,99 & $1.758,21$ & 0 \\
\hline 2014 & 37.710 & 29.811 & 79,1 & 29.817 & 79,07 & $1.758,21$ & 0 \\
\hline
\end{tabular}

Fonte: Sistema Nacional de Informações sobre Saneamento (2021) (os dados populacionais disponibilizados pelo SNIS são provenientes do IBGE).

Tabela 2 - Dados populacionais e de saneamento do município de Campos dos Goytacazes (Rio de Janeiro, Brasil), referente à série amostral 2014-2019.

\begin{tabular}{|c|c|c|c|c|c|c|c|}
\hline $\begin{array}{l}\text { Ano de } \\
\text { referência }\end{array}$ & $\begin{array}{l}\text { Pop. total do } \\
\text { município }\end{array}$ & $\begin{array}{l}\text { Pop. urbana } \\
\text { do município }\end{array}$ & $\begin{array}{l}\text { Pop. urbana } \\
\text { (\%) }\end{array}$ & $\begin{array}{l}\text { Pop. total } \\
\text { atendida } \\
\text { com esgot. } \\
\text { sanit. }\end{array}$ & $\begin{array}{l}\text { Pop. total } \\
\text { atendida } \\
\text { com esgot. } \\
\text { sanit. (\%) }\end{array}$ & $\begin{array}{l}\text { Vol. de } \\
\text { esgotos } \\
\text { coletado } \\
\left(1.000 \mathrm{~m}^{3} / \mathrm{ano}\right)\end{array}$ & $\begin{array}{l}\text { Vol. de } \\
\text { esgotos } \\
\text { tratado } \\
\left.\text { ( } 1.000 \mathrm{~m}^{3} / \mathrm{ano}\right)\end{array}$ \\
\hline 2019 & 507.548 & 458.289 & 90,3 & 421.627 & 83,07 & $12.745,00$ & $12.745,00$ \\
\hline 2018 & 503.424 & 454.566 & 90,3 & 409.125 & 81,27 & $11.899,34$ & $11.899,34$ \\
\hline 2017 & 490.288 & 442.705 & 90,3 & 398.448 & 81,27 & $11.557,56$ & $11.557,56$ \\
\hline 2016 & 487.186 & 439.904 & 90,3 & 395.914 & 81,27 & $10.864,74$ & $10.864,74$ \\
\hline 2015 & 483.970 & 437.000 & 90,3 & 369.972 & 76,45 & $10.885,96$ & $10.885,96$ \\
\hline 2014 & 480.648 & 434.000 & 90,3 & 349.571 & 72,73 & $14.583,20$ & $14.583,20$ \\
\hline
\end{tabular}

Fonte: Sistema Nacional de Informações sobre Saneamento (2021) (os dados populacionais disponibilizados pelo SNIS são provenientes do IBGE).

em sentido vertical na lâmina d'água, colocando em suspensão tanto a matéria orgânica sólida quanto as bactérias que se encontram depositadas no leito fluvial. Essa movimentação aumenta a eficiência dos processos de decomposição, elevando, assim, o consumo do oxigênio dissolvido do rio em Campos dos Goytacazes.

A segunda tendência identificada na Figura 3 refere-se ao fato de que, tanto em São Fidélis quanto em Campos dos Goytacazes, as concentrações de oxigênio dissolvido são mais elevadas durante o período de estiagem (entre junho e setembro) do que durante o período úmido (entre novembro e março). Esse resultado indica a ocorrência de duas situações distintas e complementares. Uma delas relaciona-se ao maior carreamento de esgotos para o rio via escoamento superficial, tendo como origem as áreas que não são atendidas por serviços de saneamento em ambos os municípios, em função da maior concentração de chuvas durante o período úmido. A outra situação diz respeito ao fato de que, nessa época do ano, há aumento das vazões fluviais, também em resposta ao aumento das chuvas, cujas consequências já foram apontadas no parágrafo anterior. Todos esses fatores atuam de tal modo a aumentar o consumo do oxigênio dissolvido durante o período úmido e a reduzi-lo durante o período seco.

De acordo com a Figura 4, constata-se também que as variações do comportamento do oxigênio dissolvido entre os anos do monitoramento analisados neste estudo foram 


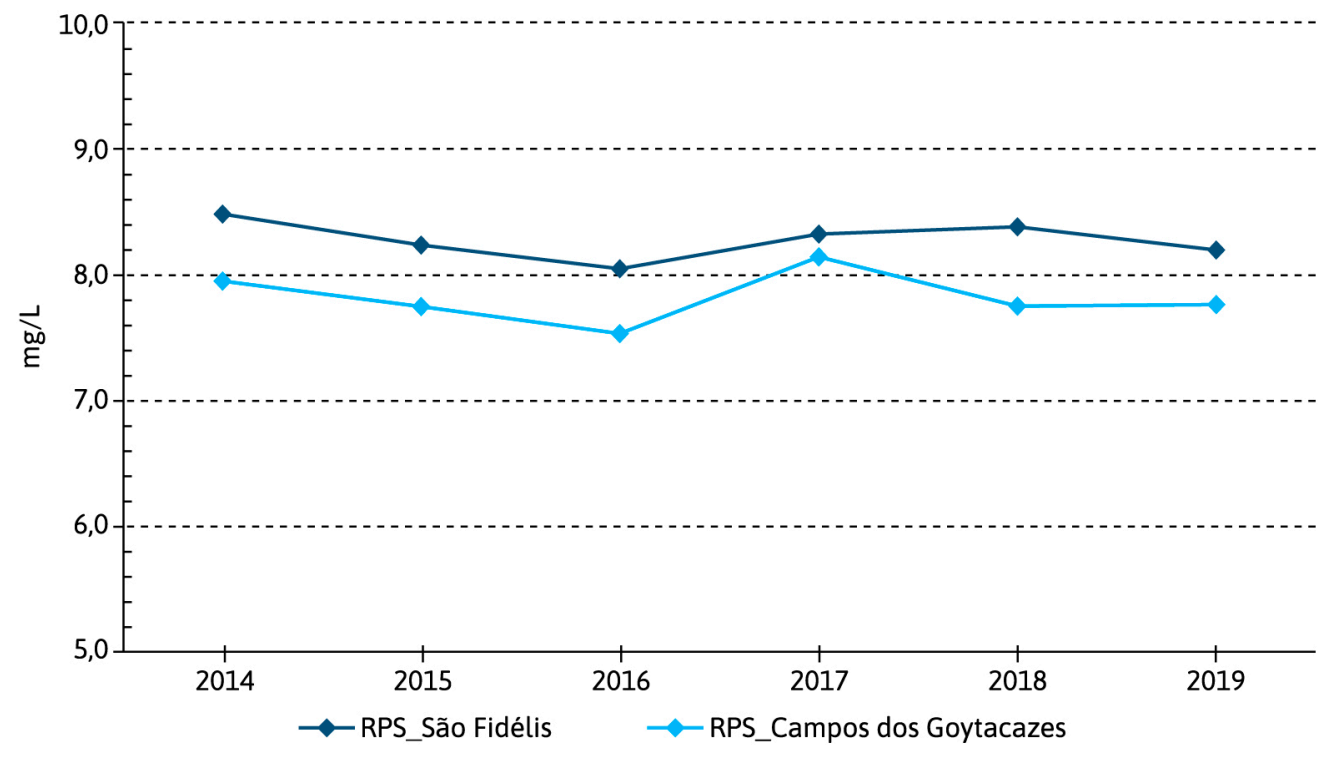

Figura 4 - Comportamento das médias anuais de oxigênio dissolvido (em $\mathrm{mg} / \mathrm{L}$ ) nos pontos amostrais do rio Paraíba do Sul (RPS), localizados nos municípios de São Fidélis e Campos dos Goytacazes (Rio de Janeiro, Brasil), referente à série amostral 2014-2019. Para tanto, foram utilizados os dados das médias anuais.

Fonte: Instituto Estadual do Ambiente (2019).

muito pequenas. Contudo, percebe-se um ligeiro decréscimo entre os anos de 2015 e 2016, o qual possivelmente reflete o declínio significativo das vazões fluviais identificado na área, que é objeto deste estudo, durante a seca que afetou a região Sudeste brasileira entre os anos de 2014 e 2016. Considerando que o declínio em questão não foi acompanhado por um decréscimo na produção e, consequentemente, no despejo dos esgotos (tratados ou não) no rio Paraíba do Sul (Tabelas 1 e 2), nessa circunstância houve uma redução da aeração das águas e, logo, do oxigênio dissolvido ali disponível, em um contexto em que, se não aumentou, a quantidade de matéria orgânica passível de ser decomposta pelas bactérias ao menos permaneceu semelhante à dos anos anteriores, causando a queda das concentrações dessa substância ao longo desse período. O declínio das vazões e suas respectivas consequências ambientais encontram-se amplamente discutidos nos trabalhos do CBH BPSI (COMITÊ DA BACIA HIDROGRÁFICA DO BAIXO RIO PARAÍBA DO SUL E ITABAPOANA, 2014) e de Leite (2015 e 2017).

\section{2 - Coliformes termotolerantes}

De acordo com Von Sperling (2014), os microrganismos presentes nos esgotos e em cursos d'água realizam diversas funções fundamentais, especialmente no que se refere à transformação da matéria orgânica por meio dos ciclos biogeoquímicos e aos processos de autodepuração da água, conforme mencionado na seção anterior. No que diz respeito à qualidade da água, verifica-se que alguns tipos de microrganismos, como bactérias, vírus, protozoários e helmintos, podem ser transmissores de doenças tanto para humanos quanto para animais.

Organismos dessa natureza, quando estão presentes nos esgotos, têm uma gênese predominantemente humana, ainda que, em menor proporção, também sejam oriundos de dejetos animais, revelando, deste modo, tanto os padrões de qualidade de saúde da 
população quanto as condições de saneamento a que ela está submetida. Assim sendo, a quantidade de patógenos presentes no esgoto de determinada localidade é variável e relaciona-se aos seguintes fatores: (a) condições socioeconômicas da população; (b) condições sanitárias; (c) região geográfica; (d) presença de indústrias agroalimentares; e (e) tipo de tratamento a que o esgoto e o lodo foram submetidos (no caso de esgotos tratados) (VON SPERLING, op. cit.). Dentro dessa perspectiva, as localidades que não dispõem de uma infraestrutura adequada de saneamento, ou seja, de serviços que promovam o tratamento e a distribuição de água tratada, assim como a coleta e o tratamento dos esgotos de forma ampla e irrestrita, são aquelas que, por uma questão de (falta de) saúde, tendem a contribuir mais com a contaminação dos efluentes que são lançados nos corpos d'água.

Pelo fato de as concentrações dos agentes patogênicos serem muito baixas nos corpos hídricos, a sua detecção em uma amostra de água é uma tarefa bastante difícil. Para contornar esse problema, passou-se a utilizar os organismos indicadores de contaminação fecal, que, apesar de serem predominantemente não patogênicos, dão uma boa noção do quanto um corpo d'água se encontra contaminado por fezes humanas ou de animais e, consequentemente, da sua potencialidade em transmitir doenças. Os organismos mais frequentemente utilizados para esse propósito são as bactérias do grupo coliforme, pois se encontram disponíveis em grande quantidade nas fezes humanas e também porque apresentam resistência ligeiramente superior à maioria das bactérias patogênicas intestinais nos ambientes aquáticos (VON SPERLING, op. cit.).

Entre os indicadores de contaminação fecal mais frequentemente utilizados estão os coliformes fecais, que correspondem a um grupo de bactérias cuja origem é o trato intestinal humano e de outros animais. O teste para a sua detecção é feito sob altas temperaturas, tendo como objetivo a eliminação de bactérias não fecais. Contudo, mesmo nessas condições, verifica-se que uma pequena quantidade delas ainda permanece, impedindo que se tenha a total garantia de que a contaminação ali evidenciada é de fato fecal. Por esse motivo, passou-se a denominar os coliformes fecais de coliformes termotolerantes (VON SPERLING, op. cit.).

Quanto às concentrações de coliformes termotolerantes consideradas aceitáveis para as águas doces destinadas ao abastecimento humano pela Resolução CONAMA 357/2005, constata-se que, para a classe 1, não pode ser ultrapassado o limite de 200 coliformes termotolerantes por 100 mililitros, em $80 \%$ ou mais de pelo menos 6 amostras, coletadas durante um período de um ano, com frequência bimestral. Em relação às classes 2 e 3, os limites que não devem ser excedidos, sob as mesmas condições, são de 1.000 e 4.000 coliformes termotolerantes, respectivamente.

No que diz respeito ao comportamento dos dados de coliformes termotolerantes analisados neste estudo, observa-se que as concentrações desses organismos foram muito mais elevadas no rio Paraíba do Sul em São Fidélis do que em Campos dos Goytacazes (Figura 5). Enquanto em São Fidélis as concentrações de coliformes termotolerantes apresentaram valores médios mensais completamente fora do padrão de enquadramento do rio definido para aquela localidade (classe 2), as concentrações desses organismos em Campos dos Goytacazes estiveram bastante abaixo do padrão previsto para aquele trecho do rio (classe 3) durante o mesmo intervalo de tempo, com exceção apenas do mês de dezembro. 


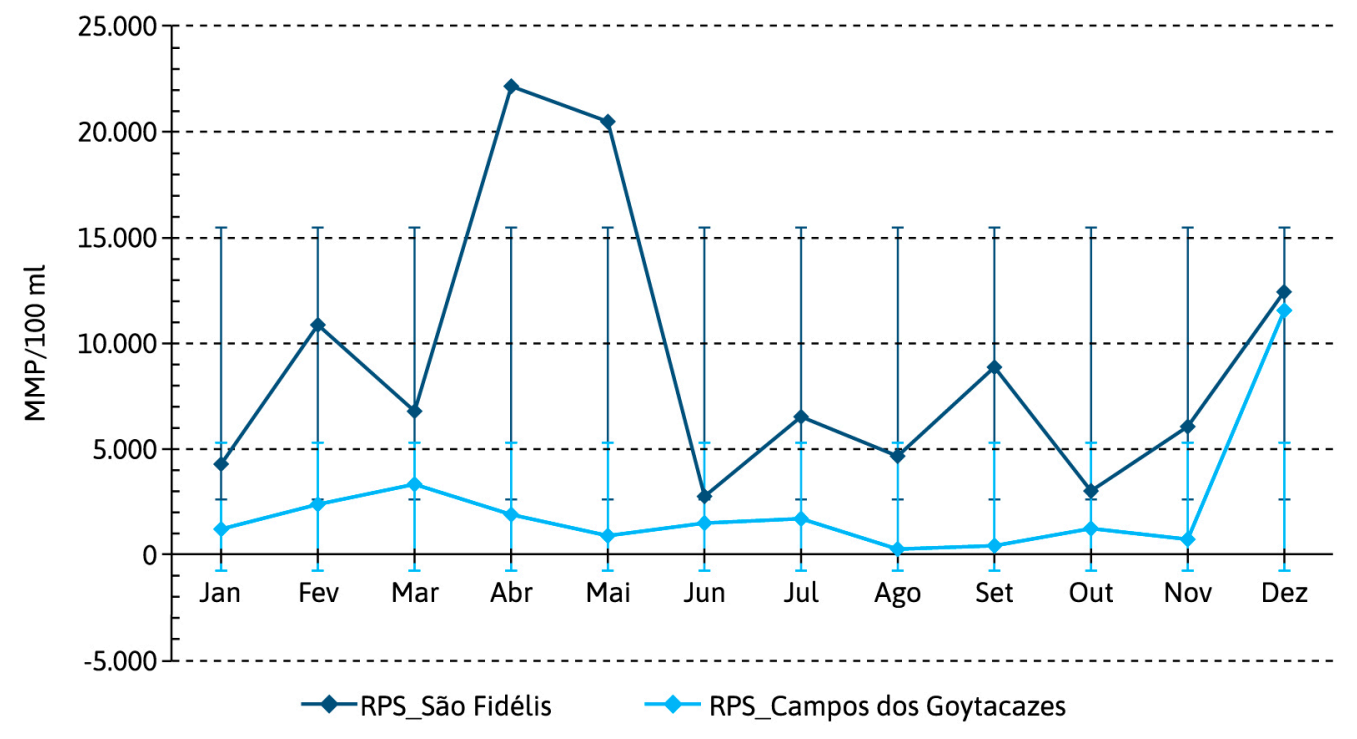

Figura 5 - Comportamento sazonal dos coliformes termotolerantes (em MMP/100 mL) nos pontos amostrais do rio Paraíba do Sul (RPS), localizados nos municípios de São Fidélis e Campos dos Goytacazes (Rio de Janeiro, Brasil), referente à série amostral 2014-2019. Para tanto, foram utilizados os dados das médias mensais com barras de desvio padrão.

Fonte: Instituto Estadual do Ambiente (2019).

Esse resultado é explicado pelas diferenças entre procedimentos utilizados pelos serviços de saneamento de cada um dos municípios considerados neste estudo, no que se refere à coleta e ao despejo dos esgotos coletados, os quais já foram aqui apontados. Sendo assim, apesar de a população de São Fidélis ter sido majoritariamente atendida por serviços de coleta de esgoto (entre 79\% e 87\% dos habitantes entre 2014 e 2019), todo o esgoto ali recolhido foi despejado nos corpos hídricos, no rio Paraíba do Sul em especial, sem ter recebido qualquer tipo de tratamento (Tabela 1).

Já em Campos dos Goytacazes, apesar de a população ser muito maior, todo o esgoto coletado recebeu tratamento antes de ter sido lançado nos corpos hídricos (Tabela 2). Ainda que a quantidade de habitantes ali residentes que não é atendida por serviços de saneamento seja maior que a população total de São Fidélis (cerca de 86 mil habitantes em 2019), o efeito de diluição das concentrações de coliformes nas águas causado pela emissão dos esgotos tratados no rio, ou seja, após a remoção desses organismos, é evidente. Além disso, o volume de água que converge para esse ponto da bacia hidrográfica proveniente das áreas posicionadas a montante, incluindo as contribuições da rede tributária do rio Paraíba do Sul, também é maior que aquele que chega até São Fidélis.

No que se refere às tendências sazonais, apresentadas no gráfico da Figura 6, ainda que à primeira vista não sejam tão claras, elas existem. Ao contrário do que se evidenciou em relação às concentrações de oxigênio dissolvido, cujas médias se mostraram bastante representativas do conjunto dos dados, as concentrações de coliformes termotolerantes apresentaram uma grande amplitude de variação entre os valores máximos e os mínimos dentro da série amostral, determinado, assim, um valor de média que, neste caso, não constitui o parâmetro estatístico que melhor lhe representa. Esse comportamento foi mais evidente em relação aos dados de São Fidélis, em especial nos meses de abril e maio. Por esse motivo, a identificação imediata do comportamento sazonal foi prejudicada, e as 


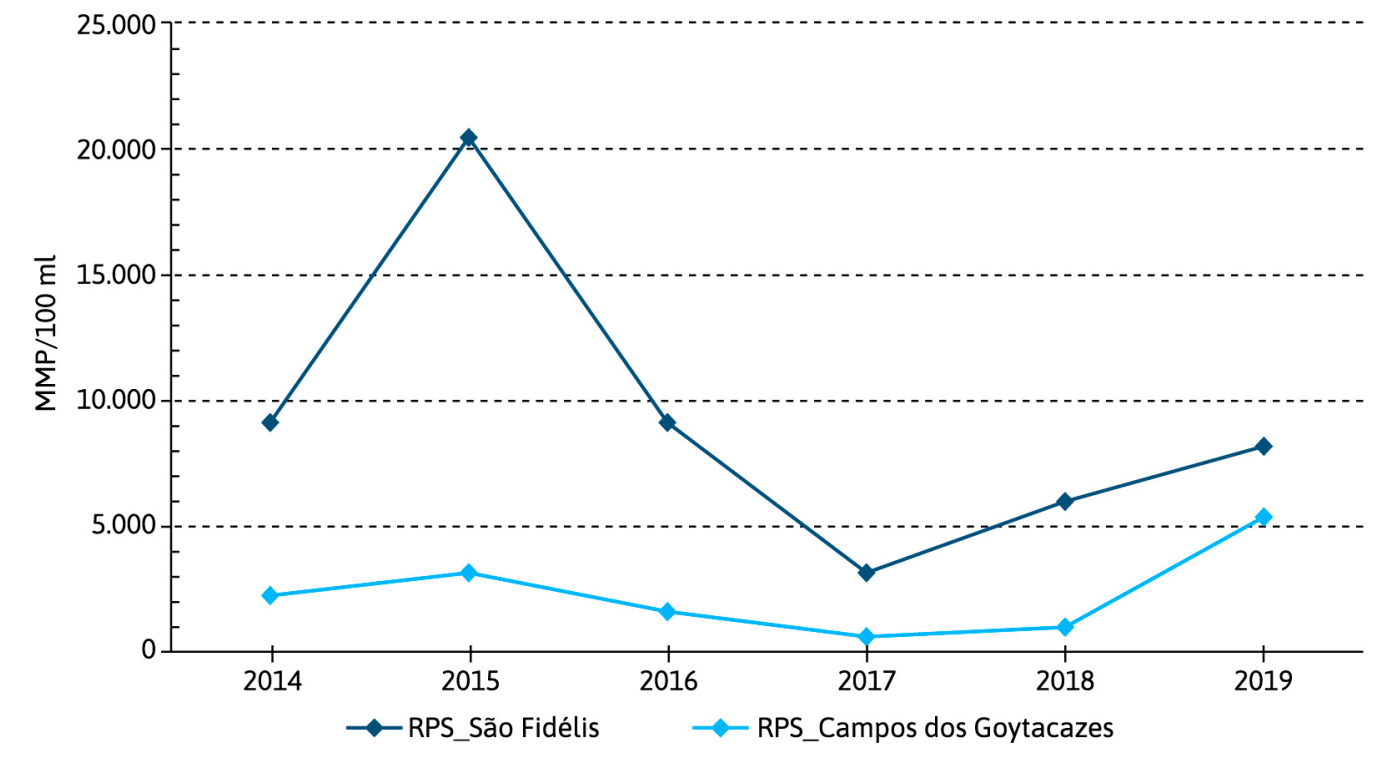

Figura 6 - Comportamento das médias anuais de coliformes termotolerantes (em MMP/100 mL) nos pontos amostrais do rio Paraíba do Sul (RPS), localizados nos municípios de São Fidélis e Campos dos Goytacazes (Rio de Janeiro, Brasil), referente à série amostral 2014-2019. Para tanto, foram utilizados os dados das médias anuais. Fonte: Instituto Estadual do Ambiente (2019).

barras de desvio padrão foram inseridas. Seja como for, observa-se que, em ambos os municípios monitorados, as concentrações de coliformes termotolerantes são mais altas durante o período úmido e mais baixas durante o período seco. Esse comportamento reflete tanto a influência do carreamento das áreas urbanizadas do entorno via escoamento superficial quanto o revolvimento do leito fluvial promovido pelo aumento das vazões durante a época chuvosa.

Quanto às variações das médias anuais, percebe-se que, em ambos os municípios monitorados, há variações anuais significativas, as quais também são explicadas pelas grandes amplitudes de variação que existem entre os dados das concentrações máximas e mínimas de coliformes termotolerantes do conjunto amostral, conforme discutido no parágrafo anterior. Esse comportamento tem relação com o fato de que a quantidade de coliformes que é disponibilizada para os corpos hídricos é fortemente influenciada por fatores locais, que estão diretamente relacionados com as atividades desenvolvidas pelos seres que produzem os coliformes. Como esses fatores são dinâmicos, eles podem alterar significativamente as concentrações desses organismos pontualmente, ou seja, durante um evento de amostragem da água, sem que haja necessariamente um efeito cumulativo de sua influência entre a coleta realizada nesse momento e a seguinte.

\section{Considerações finais}

No município de São Fidélis, que apresenta um total populacional de 38.670 habitantes (em 2019), sendo 79\% urbano e concentrado nas margens do rio Paraíba do Sul, cerca de $87 \%$ dos residentes são atendidos por serviços de esgotamento sanitário, mas todo o esgoto ali coletado é lançado nos corpos hídricos sem que tenha passado por nenhum tipo de tratamento. Tal procedimento, apesar de ainda não ter comprometido os níveis 
de oxigenação da água, que garantem a manutenção das condições de existência dos seres aquáticos, comprometeu significativamente os seus padrões de salubridade no que se refere aos usos a serem feitos por seres humanos, tendo em vista que as concentrações de coliformes termotolerantes registradas nessa localidade se encontram muito acima dos padrões estabelecidos para corpos hídricos de classe 2, conforme prescrito na Resolução CONAMA 357/2005. Esse distúrbio se intensifica durante o período úmido por causa da ocorrência de chuvas concentradas, na medida em que a rede fluvial recebe contribuições mais significativas de esgotos provenientes das áreas desprovidas de infraestrutura, os quais são carreados pelo escoamento superficial, assim como também do lodo concentrado no leito do rio, que é remobilizado em função do aumento das vazões nessa época do ano. Cabe aqui lembrar que as taxas de transporte por meio do escoamento superficial são intensificadas pela declividade das encostas (já intensamente desmatadas) e pela urbanização que impermeabiliza as superfícies.

Em Campos dos Goytacazes, que apresenta um total populacional de 507.548 habitantes (em 2019), sendo 90\% urbano e também concentrado nas margens do rio Paraíba do Sul, cerca de $83 \%$ dos residentes são atendidos por serviços de esgotamento sanitário. Contudo, ao contrário do ocorre em São Fidélis, todo o esgoto coletado no município é lançado nos corpos hídricos após ter passado por tratamento. Tal procedimento foi responsável por manter as concentrações de oxigênio dissolvido sempre dentro dos padrões e as de coliformes termotolerantes majoritariamente dentro dos padrões. Verifica-se, neste caso, que, apesar de a população de Campos dos Goytacazes ser muito maior que a de São Fidélis, e de o nível de exigência associado ao padrão de enquadramento do rio nessa localidade, que é de classe 3, ser mais baixo, há fatores ambientais que contribuem para a atenuação das concentrações de coliformes termotolerantes ali identificadas, além do próprio efeito de diluição proporcionado pelo despejo do esgoto após ter passado por tratamento. Um deles diz respeito à influência da topografia plana da área que margeia o rio Paraíba do Sul em Campos dos Goytacazes, o que reduz significativamente as taxas de produção do escoamento superficial em comparação com São Fidélis, especialmente no período de estiagem, quando os totais de chuva são ínfimos, apesar da maior urbanização do município. O outro relaciona-se às mais altas vazões do rio nesse local em relação à São Fidélis, especialmente no período úmido, que é expressão do maior volume de água disponível nesse ponto da bacia hidrográfica para diluir a concentração desses organismos.

Assim sendo, é fundamental que se dê destaque aos papéis exercidos tanto pelos serviços de saneamento quanto pelas vazões fluviais. No caso dos serviços de saneamento, os dados analisados neste estudo deixam claro que, guardadas as diferenças das características do ambiente que influenciam o comportamento dos parâmetros analisados, são nítidos os contrastes identificados na qualidade da água de um mesmo rio que corta dois municípios distintos, sendo que um descarta os esgotos após tratamento e o outro descarta sem tratá-los. Os serviços de saneamento são fundamentais, porque eles determinam o bemestar e a qualidade de vida da população, principalmente no que diz respeito à saúde. Infelizmente, o atendimento amplo e irrestrito da população brasileira por serviços de saneamento ainda não é uma realidade. De acordo com o SNIS (SISTEMA NACIONAL DE INFORMAÇÕES SOBRE SANEAMENTO, 2020), no ano de 2019, apenas 49,1\% dos esgotos gerados no Brasil receberam tratamento. Trata-se de uma proporção extremamente baixa considerando o total de 211,8 milhões de habitantes que o país possui. No que se refere à região Sudeste, nesse mesmo ano, a proporção de esgotos tratados foi de 55,5\%, 
sendo, portanto, apenas um pouco mais elevada que a média nacional, apesar de ser a região com maior densidade populacional do país.

É importante também enfatizar a importância de os serviços de saneamento serem oferecidos por empresas públicas. A privatização desse setor da gestão dos recursos hídricos, além de provocar o aumento de tarifas e desabastecimento, não garante o acesso de todos os habitantes à água. Outros problemas também notificados após a privatização referem-se ao não cumprimento de promessas feitas inicialmente e à falta de transparência no funcionamento das empresas. Por esses motivos, diversas cidades do mundo estão voltando atrás e reestatizando os seus serviços de saneamento. De acordo com a BBC (BBC NEWS BRASIL, 2017), da virada do milênio até então, foram registrados 267 casos de reestatização no mundo, os quais incluíram cidades como Berlim, Paris, Budapeste, Bamako, Buenos Aires, Maputo e La Paz.

Em relação às vazões fluviais, constata-se que, assim como os serviços de saneamento, elas têm um papel fundamental na manutenção dos padrões de qualidade da água. Contudo, o rio Paraíba do Sul vem passando por um processo de declínio das vazões de longo prazo, o qual tem sido especialmente prejudicial na região do médio/baixo curso (COMITÊ DA BACIA HIDROGRÁFICA DO BAIXO RIO PARAÍBA DO SUL E ITABAPOANA, 2014; LEITE, 2017, 2019) e tem relação com o aumento das captações de água dentro da bacia como um todo, em particular pelas hidrelétricas e pela transposição existente no médio curso, que desvia cerca $70 \%$ da água para atender ao setor elétrico e ao abastecimento da Região Metropolitana do Rio de Janeiro. Contudo, há também fatores agravantes desse processo na região que foi objeto desta análise. Enquanto em São Fidélis se evidencia um intenso assoreamento da calha fluvial, em Campos dos Goytacazes o amplo processo de drenagem das áreas úmidas que margeavam o Paraíba causou o rebaixamento do nível freático local que é responsável por manter a sua perenidade. Caso o processo de declínio das vazões tenha continuidade, há possibilidade de que tanto a escassez hídrica, que já se evidencia localmente, tenda a se intensificar, tornando as históricas disputas pela água cada vez mais acentuadas, quanto os serviços de saneamento sejam prejudicados, na medida em que o tratamento da água e dos esgotos se tornará cada vez mais difícil e caro.

\section{Referências bibliográficas}

BBC NEWS BRASIL. Enquanto Rio privatiza, por que Paris, Berlim e outras 265 cidades reestatizaram saneamento? BBC News Brasil, Rio de Janeiro, 2017. Disponível em: <https://www.bbc.com/portuguese/ brasil-40379053>. Acesso em: 14 mar. 2021.

BRASIL. Ministério do Meio Ambiente. Conselho Nacional do Meio Ambiente - CONAMA. Resolução $n^{\circ} 357$, de 17 de março de 2005. Dispõe sobre a classificação dos corpos de água e diretrizes ambientais para o seu enquadramento, bem como estabelece as condições e padrões de lançamento de efluentes, e dá outras providências, Diário Oficial da República Federativa do Brasil, Brasília, DF, 2005. Disponível em: <http://www2.mma.gov.br/port/conama/legiabre.cfm?codlegi=459>. Acesso em: 06 mar. 2020.

COMITÊ DA BACIA HIDROGRÁFICA DO BAIXO RIO PARAÍBA DO SUL E ITABAPOANA - CBH BPSI. Nota Técnica CBH BPSI - Decisão do Comitê do Baixo Paraíba do Sul e Itabapoana acerca da redução de vazões de chegada na transposição de Santa Cecília. Campos dos Goytacazes: $\mathrm{CBH}$ BPSI e AGEVAP, 2014. Disponível em: <http://cbhbaixoparaiba.org.br/conteudo/Bol_Tecnico_CBHBPSI_v1-n1-jun2014.pdf>. Acesso em: 05 set. 2016.

COMITÊ DE INTEGRAÇÃO DA BACIA HIDROGRÁFICA DO RIO PARAÍBA DO SUL - CEIVAP. Enquadramento vigente dos rios federais e estaduais na Bacia do Rio Paraíba do Sul. Resende: CEIVAP, 2020. Disponível em: <https://www.ceivap.org.br/images/Mapa_enquadramento.png >. Acesso em 15 jun. 2021. 
COMPANHIA AMBIENTAL DO ESTADO DE SÃO PAUlO - CETESB. Mortandade de peixes: matéria orgânica e nutrientes. São Paulo: CETESB, 2021. Disponível em: <https://cetesb.sp.gov.br/ mortandade-peixes/alteracoes-fisicas-e-quimicas/materia-organica-e-nutrientes/\#: :text=A\%20 matéria\%20orgânica\%20sofre\%20um,do\%20oxigênio\%20presente\%20no\%20meio.\&text=Com\%20 a\%20decomposição\%20da\%20matéria,superiores\%20para\%20o\%20seu\%20crescimento >. Acesso em: 10 mar. 2021.

ESTEVES, F. A.; FURTADO, A. L. S. Oxigênio dissolvido. In: ESTEVES, F. A. (Coord.). Fundamentos de Limnologia. 3. ed. Rio de Janeiro: Interciência, 2011. p. 167-191.

FRANCHI, J. G.; SÍGOLO, J. B.; MOTTA, J. F. M. Diagnóstico das turfas no Brasil: histórico da utilização, classificação, geologia e dados econômicos. Revista Brasileira de Geociencias, São Paulo, v. 36, n. 1, p. 179-190, 2006.

GOUDIE, A. S.; VILES, H. A. Subsidence in the Anthropocene. In: GOUDIE, A. S.; VILES, H. A. (Ed.). Geomorphology in the Anthropocene. 1st ed. Cambridge: Cambridge University Press, 2016. p. 57-70.

INSTITUTO ESTADUAL DO AMBIENTE - INEA. Qualidade das Águas por Região Hidrográfica (RHs). Rio de Janeiro: INEA, 2019. Disponível em: <http://www.inea.rj.gov.br/ar-agua-e-solo/qualidade-dasaguas-por-regiao-hidrografica-rhs/>. Acesso em: 13 jan. 2020.

LAMEGO, A. R. O homem e o brejo. 1. ed. (fac-sim). Rio de Janeiro: Instituto Brasileiro de Geografia e Estatística (IBGE), 2007. 204 p.

LEITE, A. F. Discharge decline, hydric availability, risks and vulnerability in the low Paraíba do Sul River, Rio de Janeiro, Brazil. In: INTERNATIONAL GEOGRAPHICAL UNION REGIONAL CONFERENCE - GEOGRAPHY, CULTURE AND SOCIETY FOR OUR FUTURE EARTH, 15., 2015, Moscou. Anais... Moscou, 2015.

LEITE, A. F. Gestão dos recursos hídricos e desastres relacionados à água na baixada Campista. In: ENCONTRO NACIONAL DOS PROGRAMAS DE PÓS-GRADUAÇÃO EM GEOGRAFIA (ENANPEGE) - GEOGRAFIA, CIÊNCIA E POLÍTICA: DO PENSAMENTO À AÇÃO, DA AÇÃO AO PENSAMENTO, 12., 2017, Porto Alegre. Anais... Porto Alegre, 2017.

LEITE, A. F. Estruturas hidráulicas, gestão dos recursos hídricos e desastres relacionados à água na região do baixo curso do rio Paraíba do Sul (estado do Rio de Janeiro): uma análise fundamentada no desastre deflagrado pela inundação de 2007. Ambientes: Revista de Geografia e Ecologia Política, Francisco Beltrão, v. 1, n. 1, p. 146-190, 2019.

MENDONÇA, J. C. Inundações na baixada Campista. In: TOTTI, M. E. F.; SOFFIATI, A. (Org.). Gestão de águas no baixo rio Paraíba do Sul: região hidrográfica IX do estado do Rio de Janeiro. 1. ed. Campos dos Goytacazes: Essentia, 2014. p. 91-127.

NICKNIG, W. A. Evolução da rede de monitoramentos hidrométricos da Região Norte Fluminense. 2016. Trabalho de Conclusão de Curso (Bacharelado em Geografia)-Universidade Federal Fluminense, 2016.

SISTEMA NACIONAL DE INFORMAÇÕES SOBRE SANEAMENTO - SNIS. Diagnóstico dos serviços de águas e esgotos - 2019. Brasília: Ministério do Desenvolvimento Regional, 2020. Disponível em: $<$ http://www.snis.gov.br/diagnosticos>. Acesso em: 14. mar. 2021.

SISTEMA NACIONAL DE INFORMAÇÕES SOBRE SANEAMENTO - SNIS. SNIS - Série Histórica. Brasília: Ministério do Desenvolvimento Regional, 2021. Disponível em: <http://app4.mdr.gov.br/ serieHistorica/\#>. Acesso em: 11 mar. 2021.

SUMMERFIELD, M. A. Fluvial processes. In: SUMMERFIELD, M. A. (Ed.). Global geomorphology. 1st ed. Essex: Pearson Education Limited - Prentice Hall, 1991. p. 191-204.

VON SPERLING, M. Estudos e modelagem da qualidade da água de rios. 2. ed. Belo Horizonte: UFMG, 2014. 588 p.

VON SPERLING, M. Introdução à qualidade das águas e ao tratamento de esgotos. 4. ed. Belo Horizonte: UFMG, 2018. 470 p. 
SOBRE OS AUTORES

Bruna Almeida Ribeiro (RIBEIRO, B. A.). Mestranda do Programa de Pós-Graduação em Geografia da Universidade Federal Fluminense, em Campos dos Goytacazes.

Adriana Filgueira Leite (LEITE, A. F.). Professora do Departamento de Geografia e do Programa de Pós-Graduação em Geografia da Universidade Federal Fluminense, em Campos dos Goytacazes. Coordenadora do Laboratório de Geomorfologia, Hidrologia e Recursos Hídricos (GEOHIDRO). 